\title{
COMUNIDADE DE FUNGOS MICORRÍZICOS ARBUSCULARES: DIVERSIDADE, COMPOSIÇÃO E GLOMALINA EM ÁREA REVEGETADA COM SESBÂNIA ${ }^{(1)}$
}

\author{
Cristiane Figueira da Silva ${ }^{(2)}$, Jean Luiz Simões de Araújo ${ }^{(3)}$, Eliane Maria Ribeiro da \\ Silva $^{(3)}$, Marcos Gervasio Pereira ${ }^{(4)}$, Jolimar Antonio Schiavo(5), Marta Simone Mendonça \\ de Freitas ${ }^{(6)}$, Orivaldo José Saggin-Junior ${ }^{(3)} \&$ Marco Antônio Martins $^{(7)}$
}

\begin{abstract}
RESUMO
A composição de comunidades e diversidade de fungos micorrízicos arbusculares (FMAs) pode ser influenciada por diversos fatores como o clima, a biota do solo e as plantas hospedeiras. Este estudo objetivou avaliar a influência da revegetação de uma cava de extração de argila com Sesbania virgata (SV) em plantios puro e consorciado com Eucalyptus camaldulensis (EC) e Acacia mangium (AM), na composição e diversidade de fungos micorrízicos arbusculares (FMAs), bem como na quantidade da proteína do solo relacionada à glomalina (PSRG). $O$ delineamento experimental utilizado foi em blocos casualizados com quatro tratamentos (plantio puro de SV 100SV; consórcio de SV + EC - 50SV:50EC; consórcio de SV + AM - 50SV:50AM; e área degradada com vegetação espontânea - ADVE), com três repetições. A revegetação da cava de extração de argila com $\mathrm{SV}$, em plantios puro ou consorciado, reduziu a abundância de esporos e a dominância de espécies (Índice de Simpson - IDS) e aumentou a riqueza de espécies de FMAs e o índice de diversidade de Shannon e Wiener. Além disso, aumentou a quantidade de proteína do solo relacionada à glomalina, quando comparada a área degradada com vegetação espontânea.
\end{abstract}

Termos de indexação: mineração, recuperação de áreas degradadas, Sesbania virgata, microrganismos.

(1) Parte da tese do primeiro autor apresentada ao Programa de Pós-Graduação em Produção Vegetal da Universidade Estadual do Norte Fluminense Darcy Ribeiro - UENF. Recebido para publicação em 4 de fevereiro de 2013 e aprovado em 11 de dezembro de 2013.

(2) Pós-Doutoranda do programa de Pós-Graduação em Ciências Ambientais e Florestais, Universidade Federal Rural do Rio de Janeiro - UFRRJ. BR 465, km 7. CEP 23890-000 Seropédica (RJ). Bolsista da CAPES. E-mail: cfigueirasilva@yahoo.com.br

(3) Pesquisador, Embrapa Agrobiologia. BR 465, km 7. CEP 23890-000 Seropédica (RJ). E-mail: jean.araujo@embrapa.br; eliane.silva@embrapa.br; orivaldo.saggin@embrapa.br

(4) Professor Associado IV, Departamento de Solos, UFRRJ. Bolsista do CNPq e FAPERJ. E-mail: gervasio@ufrrj.br

(5) Professor Associado IV, Universidade Estadual de Mato Grosso do Sul - UEMS. Rodovia Aquidauana, km 12. CEP $79200-000$ Aquidauana (MS). E-mail: schiavo@uems.br

(6) Professora Associada, UENF. Av. Alberto Lamego, 2.000. CEP 28013-602 Campos dos Goytacazes (RJ). E-mail: msimone@uenf.br

(7) Professor Titular, UENF. E-mail: marco@uenf.br 


\title{
SUMMARY:ARBUSCULARMYCORRHIZAL FUNGI:DIVERSITY, COMPOSITION AND GLOMALIN AREA AND DEGRADED REVEGETATED WITH SESBÂNIA
}

\begin{abstract}
The community composition and diversity of arbuscular mycorrhizal fungi (AMF) can be affected by several factors, including the climate, soil biota and host plants. This study aimed to evaluate the influence of Sesbania virgata (SV) revegetation in pure and intercropped with plantation Eucalyptus camaldulensis (EC) and Acacia mangium (AM), in the composition and diversity of arbuscular mycorrhizal fungi (AMF), and the amount glomalin-related soil protein $(G R S P)$ in an area damaged by clay extraction. The experimental design was a randomized block with four treatments (planting pure $S V-100 S V$ ); consortium of $S V+E C$ 50SV: 50EC; consortium AMSV+-50SV: 50AM) and degraded area with natural vegetation - ADVE) and three replications. Revegetation of mining digging clay with SV in pure or intercropped planting reduced the abundance of spores and increased species diversity of arbuscular mycorrhizal fungi. Furthermore, increased the amount of glomalin-related soil protein compared with the degraded area and spontaneous vegetation.
\end{abstract}

Index terms: mine, recovery of degraded areas, Sesbania virgata, microorganisms.

\section{INTRODUÇÃO}

Sesbania virgata é uma leguminosa que se associa a bactérias fixadoras de nitrogênio, de ciclo curto (oito a nove anos), nativa dos pampas argentinos (Branzini et al., 2012) e de ocorrência natural no Brasil (Santos et al., 1997). De acordo com Santiago et al. (2009) e Rodrigues et al. (2003), quando em consórcio com plantas não leguminosas, $S$. virgata pode contribuir tanto para sobrevivência dessas plantas quanto para transferência de parte do $\mathrm{N}$ fixado biologicamente. Além disso, plantios consorciados dessa espécie com leguminosas ou não leguminosas podem aumentar a deposição de nutrientes via serapilheira, quando comparados a seus monocultivos (Silva, 2009).

Segundo Samôr (1999) e Coutinho et al. (2006), essa espécie é importante na recuperação de cavas de extração de argila pela sua frequência de ocorrência em cavas abandonadas à revegetação natural, boa disponibilidade de sementes e capacidade de associarse a bactérias fixadoras de $\mathrm{N}_{2}$ atmosférico. Diversos estudos têm demonstrado bom estabelecimento e crescimento dessa espécie nesse tipo de ambiente degradado (Coutinho et al., 2006; Schiavo et al., 2010).

Também é importante a influência do plantio de S. virgata sobre as características edáficas de áreas degradadas. Alguns autores têm evidenciado os efeitos da revegetação de cavas de extração de argila, com monocultivos e, ou, consórcios de S. virgata sobre as propriedades químicas e físicas do solo (Santiago et al., 2009; Silva, 2009). No entanto, pouco se sabe a respeito do efeito desses plantios sobre a microbiota edáfica, como os fungos micorrízicos arbusculares (FMAs). Esses fungos desempenham papéis importantes nos ecossistemas com plantas terrestres pela aquisição de nutrientes e tolerância a estresses químicos, físicos e biológicos que eles promovem aos seus vegetais hospedeiros. Em razão do aumento da biomassa vegetal que proporcionam, eles incrementam a deposição e dinâmica de nutrientes ao solo por meio da serapilheira e colaboram com o aumento do sequestro de $\mathrm{C}$ da atmosfera (Leake et al., 2004).

Silva et al. (2012) observaram em cava de extração de argila que plantios puros e, ou, consorciados de Acacia mangium e Eucalyptus camaldulensis influenciaram tanto o número de esporos de FMAs quanto a diversidade de espécies na comunidade. Além disso, aumentaram a quantidade de proteína do solo relacionada à glomalina (PSRG) em relação à área da cava com vegetação espontânea. A glomalina é uma glicoproteína produzida pelos FMAs (Wright et al., 2007), que se acumula no solo após o processo de decomposição das hifas e dos esporos, por microrganismos edáficos (Driver et al., 2005). Essa proteína funciona no solo como um ligante orgânico (Purin, 2005) e está relacionada com a estabilidade de agregados e com o C e N do solo (Wright et al., 2007; Bedini et al., 2007; Fokom et al., 2012). De acordo com Sousa et al. (2012), a quantidade de glomalina produzida pelos FMAs pode ser influenciada por diferentes fatores, como as características do solo, as condições climáticas, o sistema de uso do solo, as práticas de manejo agrícola, a presença e o tipo de vegetação.

Assim, o objetivo deste estudo foi avaliar a influência da revegetação de uma cava de extração de argila com $S$. virgata em plantios puros e consorciados com Eucalyptus camaldulensis (EC) e Acacia mangium (AM), na composição e diversidade da comunidade de FMAs, bem como na quantidade de proteína do solo relacionada à glomalina (PSRG), em Campos dos Goytacazes, RJ.

\section{MATERIAL E MÉTODOS}

As amostras de solo utilizadas para realização deste trabalho foram coletadas em uma cava de 
extração de argila pertencente à cerâmica Stilbe Ltda, localizada no distrito de Poço Gordo ( $21^{\circ} 50^{\prime}$ 28,5" S; $\left.41^{\circ} 14^{\prime} 31,4^{\prime \prime} \mathrm{W}\right)$, município de Campos dos Goytacazes, RJ. O clima da região norte fluminense é classificado, de acordo com Köppen, como do tipo Aw, tropical quente e úmido, com período seco no inverno e chuvoso no verão e com precipitação pluvial anual em torno de $1.020 \mathrm{~mm}$. As médias de temperatura e precipitação pluvial da área em estudo, registradas no período de maio de 2006 a junho de 2007 , foram de $24,1^{\circ} \mathrm{C}$ e $86,6 \mathrm{~mm}$, respectivamente.

O solo original da área da cava em estudo é classificado como um Cambissolo Háplico sódico gleico, com aproximadamente $3 \mathrm{~m}$ de profundidade. A camada superficial do solo contendo a maior parte da matéria orgânica foi retirada e devolvida ao fundo da cava, após a extração da argila. A cava foi nivelada mecanicamente e após um período de pousio de dois anos realizou-se o preparo da área com uma aração e duas gradagens. A cava foi revegetada, em agosto de 2002, com Sesbania virgata (SV) em plantios puro e consorciado com Eucalyptus camaldulensis (EC) e Acacia mangium (AM) (Schiavo, 2005), utilizando-se um espaçamento de $2 \mathrm{~m}$ entre plantas e $3 \mathrm{~m}$ entrelinhas $(2 \times 3)$. Fez-se uma adubação nas covas com fosfato de Araxá, sendo a dose aplicada equivalente a $100 \mathrm{mg} \mathrm{kg}^{-1}$ de solo.

O delineamento experimental utilizado foi de blocos ao acaso com quatro tratamentos e três repetições, sendo os tratamentos: plantio puro de $S$. virgata (100SV); consórcio de S. virgata + Eucalyptus camaldulensis (50SV:50EC); S. virgata + Acacia mangium (50SV:50AM); e área degradada com vegetação espontânea (ADVE) [predomínio de Brachiaria mutica (Forsk.) Stapf.]. A bordadura foi composta por duas linhas de plantas de $E$. camaldulensis entre cada parcela. Cada parcela experimental foi constituída por 16 plantas.

Na fase de produção de mudas, as espécies foram inoculadas com FMAs (Glomus macrocarpum, Glomus etunicatum e Entrophospora colombiana), previamente isolados de uma área de extração de argila, pertencente à cerâmica Caco Manga Ltda., localizada no distrito de Ururaí, no município de Campos dos Goytacazes, RJ. O isolado, pertencente ao banco de inóculo do laboratório de solos da UENF, foi multiplicado em plantas de Brachiaria bryzantha em mistura de solo + areia na proporção de 1:2 (v:v). Além dos FMAs, as leguminosas foram inoculadas (na semente) com estirpe específica de rizóbio para cada espécie de leguminosa, sendo BR 3609 e BR 6009 para A. mangium e BR 5401 para S. virgata. As estirpes foram provenientes da coleção de culturas da Embrapa Agrobiologia, Seropédica, RJ.

A amostragem foi realizada na entrelinha dos plantios em setembro de 2006, na profundidade de $0-5 \mathrm{~cm}$. Em cada parcela, foram coletadas 10 amostras simples de solo, que misturadas resultaram em uma amostra composta por parcela (total de 12 parcelas).
No ato da amostragem, as parcelas com os plantios das espécies arbóreas apresentavam-se com quatro anos de idade, enquanto a ADVE com seis anos.

As amostras de solo foram previamente secas à sombra, acondicionadas em sacolas plásticas e armazenadas a $10^{\circ} \mathrm{C}$, para isolamento de esporos de FMA, quantificação da proteína do solo relacionada à glomalina (PSRG) e encaminhamento para análise das características químicas (Quadro 1).

De cada amostra foram retirados $50 \mathrm{~cm}^{3}$ de solo para as extrações dos esporos dos FMAs, seguindo a técnica de peneiramento úmido (Gerdermann \& Nicolson, 1963). Após a contagem, os esporos foram transferidos para uma placa de Petri e uma quarta parte do total deles foi separada aleatoriamente. Esses foram divididos em dois grupos, sendo um grupo disposto na lâmina com álcool polivinil em lactoglicerol (PVLG), sob uma lamínula, e o outro grupo, disposto nessa mesma lâmina, com reagente de Melzer, sob outra lamínula.

Os esporos foram observados em microscópio ótico com iluminação de campo-claro e objetiva de imersão. A identificação das espécies de FMAs foi feita de acordo com Schenck \& Perez (1988) e utilizando a descrição morfológica disponível na página da International Culture Collection of Arbuscular Mycorrhizal Fungi (http://invam.caf.wwu.edu/). Os caracteres taxonômicos observados foram: número e tipo de camadas das paredes dos esporos e sua reação ao reagente de Melzer; características das paredes internas, quando presentes; morfologia da hifa de sustentação do esporo; e variação da cor e do tamanho dos esporos.

Calcularam-se a riqueza média de espécies de FMAs e os índices de riqueza de espécies Shannon-Wiener e de dominância de Simpson em cada amostra de solo. Além disso, foram avaliadas a abundância de esporos (AE), a abundância de esporos de cada espécie (NE) e o índice de abundância e frequência (IAF) para cada espécie, em cada tratamento. $\mathrm{O}$ índice de abundância e o de frequência (IAF) foram calculados para cada espécie pela soma da frequência relativa $\left(\mathrm{FR}_{\mathrm{j}}\right)$ e densidade relativa $\left(\mathrm{DR}_{\mathrm{j}}\right.$ ) de seus esporos, multiplicado por 100 (Koske et al., 1997). A frequência relativa de cada espécie de FMA $\left(\mathrm{FR}_{\mathrm{i}}\right)$ foi estimada, como a proporção da soma das frequências para todas as espécies (Brower et al., 1990), representada pela equação:

$$
F R i=f i / \Sigma f \text {, }
$$

em que FRi é a frequência de ocorrência relativa de uma dada espécie i; fi, a frequência de ocorrência de uma dada espécie i; e $\Sigma f$, a soma das frequências de todas as espécies. As espécies foram classificadas em quatro categorias, de acordo com as suas contribuições na comunidade total de esporos: nenhuma importância $(\mathrm{IAF}=0)$; pouca importância $(0<\mathrm{IAF} \leq 10)$; moderada importância $(10<\mathrm{IAF} \leq 30)$; e grande importância (IAF>30) (Koske \& Gemma, 1997) (Quadro 2). 
Quadro 1. Características químicas da camada 0-5 cm do solo da área degradada pela extração de argila, com vegetação espontânea (ADVE) e revegetada com S. virgata (100SV) em plantio puro e consorciado com Acacia mangium (50SV:50AM) e Eucalyptus camaldulensis (50SV:50EC)

\begin{tabular}{|c|c|c|c|c|c|c|c|c|}
\hline Sistema & pH & COT & $\mathbf{N}$ & $\mathrm{Ca}^{2+}$ & $\mathbf{M g}^{2+}$ & $\mathrm{H}+\mathrm{Al}$ & $\mathbf{P}$ & $\mathbf{K}$ \\
\hline & & \multicolumn{2}{|c|}{$\mathrm{g} \mathrm{kg}^{-1}$} & \multicolumn{3}{|c|}{$-\mathrm{cmol}_{\mathrm{c}} \mathrm{dm}^{-3}$} & \multicolumn{2}{|c|}{$\mathrm{mg} \mathrm{kg}^{-1}$} \\
\hline $100 \mathrm{SV}$ & 5,10 & 24,35 & 1,75 & 5,90 & 4,64 & 4,70 & 22,21 & 297 \\
\hline 50SV:50EC & 5,40 & 34,41 & 1,80 & 5,53 & 4,78 & 4,08 & 23,65 & 270 \\
\hline 50SV:50AM & 5,20 & 29,25 & 1,60 & 7,55 & 3,46 & 4,66 & 20,60 & 280 \\
\hline ADVE & 6,82 & 11,92 & 0,50 & 3,85 & 2,48 & 0,95 & 14,66 & 155 \\
\hline
\end{tabular}

COT: carbono orgânico total.

Quadro 2. Riqueza total de espécies de FMAs, índice de diversidade de Shannon-Wiener $(\mathrm{H})$ e índice de dominância de Simpson $\left(\mathrm{D}_{\mathrm{s}}\right)$, em amostras de solo de área degradada pela extração de argila, com vegetação espontânea (ADVE) e revegetada com S. virgata (100SV), em plantios puro e consorciado com A. mangium (50SV:50AM) e $E$. camaldulensis (50SV:50EC)

\begin{tabular}{lccc}
\hline Sistema & Riqueza total & $\mathrm{H}$ & $\mathrm{D}_{\mathrm{s}}$ \\
\hline 100SV & 5 & 0,32 & 0,49 \\
50SV:50EC & 11 & 0,57 & 0,34 \\
50SV:50AM & 8 & 0,56 & 0,28 \\
ADVE & 2 & 0,09 & 0,89 \\
\hline
\end{tabular}

Médias seguidas de mesma letra na coluna não diferem pelo teste Scott-Knott a $5 \%$.

A glomalina no solo foi quantificada como proteína do solo relacionada à glomalina (PSRG). Duas frações de PSRG (glomalina facilmente extraível - GFE e glomalina total - GT) foram diferenciadas em razão das condições de extração (Wright \& Updahyaya, 1998; Rillig, 2004). A proteína do solo relacionada à glomalina facilmente extraível (PSRG-FE) foi obtida a partir da extração em autoclave, utilizando-se $1 \mathrm{~g}$ de solo e $8 \mathrm{~mL}$ de solução citrato de sódio $20 \mathrm{mmoL} \mathrm{L}^{-1}(\mathrm{pH} 7,4)$, a $121{ }^{\circ} \mathrm{C}$, por $30 \mathrm{~min}$. A quantidade de proteína do solo relacionada à glomalina total (PSRG - T) foi obtida utilizando-se $1 \mathrm{~g}$ de solo e $8 \mathrm{~mL}$ de citrato de sódio $50 \mathrm{mmoL} \mathrm{L}^{-1}$ (pH 8,0), a $121{ }^{\circ} \mathrm{C}$, por $60 \mathrm{~min}$. Para extração dessa fração, foram necessários mais de um ciclo de autoclavagem (três a 10 ciclos, dependendo da amostra), até que a amostra atingisse a cor amarela-clara. Em ambas as frações, após a autoclavagem, foi realizada centrifugação a $5.000 \mathrm{~g}$ por 20 min, sendo o sobrenadante removido para posterior quantificação da proteína. A quantificação da glomalina foi efetuada pelo método Bradford (1976), modificada por Wright et al. (1996), disponível em http://www.usda.gov, usando como padrão albumina de soro de bovino (BSA). As concentrações da glomalina, para ambas as frações, foram corrigidas para mg g ${ }^{-1}$ de solo, considerando-se o volume total de sobrenadante e a massa seca do solo.
Os dados foram avaliados quanto à homocedastia, pelo teste de Cochran (Snedecor \& Cochran, 1989), e distribuição normal dos resíduos, pelo teste de Lilliefors (Campos, 1979). Posteriormente, foram submetidos à análise de variância e ao teste de médias Scott-Knott $(\alpha=0,05)$. A análise de correspondência e a de similaridade (Medida de similaridade: Gower) foram feitas pelo programa Past (Hammer et al., 2004).

\section{RESULTADOS E DISCUSSÃO}

Os plantios, de maneira geral, quando comparados à ADVE, reduziram a dominância da comunidade de espécies de FMAs, representada pelo índice de dominância de Simpson $\left(\mathrm{D}_{\mathrm{s}}\right)$, e aumentaram o número de espécies (riqueza total - RT) e a diversidade, inferida pelo índice de Shannon-Wiener (H) (Quadro 2). Em razão do aumento no número de espécies de FMAs nos plantios, pode ter ocorrido maior competição interespecífica, o que possivelmente reduziu a dominância de uma ou poucas espécies nesses ambientes, quando comparados à ADVE. Carneiro et al. (2012) também observaram esse padrão para os índices de dominância de Simpson e de Shannon e Wiener em áreas degradadas e revegetadas, no nordeste do Brasil. Esse fato evidencia os benefícios à comunidade de FMAs, promovidos pela revegetação da área da cava com plantios puro e consorciado de $S$. virgata.

Observou-se que os plantios consorciados 50SV:50EC e 50SV:50AM apresentaram maior riqueza total e H que o plantio puro 100SV (Quadro 2). Esse padrão pode ser decorrente da maior diversidade de plantas nos consórcios, tendo em vista que na ADVE ocorre o predomínio de uma única espécie de gramíneas (B. mutica). Wu et al. (2007) e Souza et al. (2010) também observaram maior diversidade de FMAs em sistemas com maior diversidade de espécies vegetais.

Maior diversidade de espécies de FMAs em determinada área pode permitir melhor desempenho das espécies vegetais na absorção de nutrientes e água do solo, pois, embora não ocorra especificidade 
hospedeira, ou seja, uma espécie de planta pode ser colonizada por qualquer espécie de FMA, os efeitos da simbiose podem diferir conforme a combinação plantafungo (Costa et al., 2001; Pouyú-Rojas et al., 2006). Além disso, as espécies de fungos diferem na produção de hifas (Nogueira \& Cardoso, 2000; Piotrowski et al., 2004), padrão que além de influenciar na nutrição vegetal, influencia nas propriedades físicas do solo, como a agregação (Wright \& Upadhyaya, 1998; Piotrowski et al., 2004). A agregação é essencial para manter a porosidade do solo, permitindo a troca gasosa e infiltração de água, facilitando o ciclo biogeoquímico (Diaz-Zorita et al., 2002).

Na figura 1, está evidenciado o grau de semelhança entre os sistemas estudados, no que diz respeito à composição de espécies de FMAs. Observou-se a formação de dois grupos, em que o primeiro grupo, que integrou a ADVE, apresentou uma distância de ligação superior a 70 \% em relação ao segundo grupo, que se constituiu pelos plantios consorciados (50SV:50EC e 50SV:50AM) e pelo plantio puro (100SV). No que se refere ao segundo grupo, verificou-se que os consórcios (50SV:50EC e 50SV:50AM) apresentaram maior similaridade entre si, tendo uma distância de ligação de apenas $24 \%$. Esses plantios, por sua vez, se distanciaram do plantio puro (100SV) em torno de $30 \%$. Maior similaridade entre os consórcios pode ser

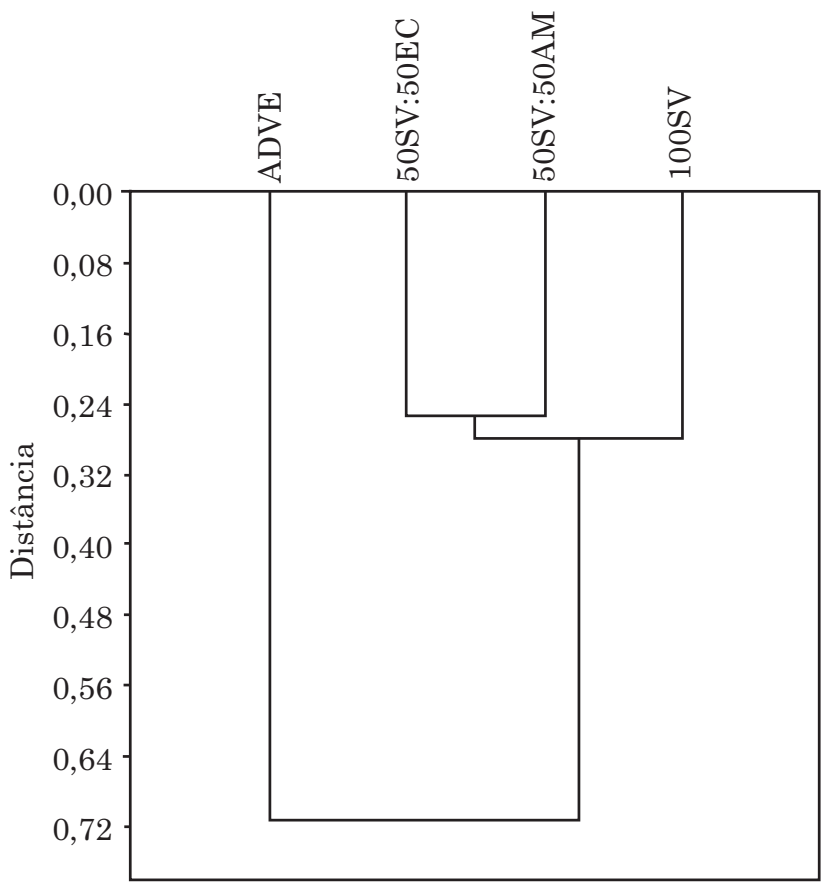

Figura 1. Dendrograma da ocorrência de espécies de FMAs em amostras de solo de área degradada pela extração de argila, com vegetação espontânea (ADVE) e revegetada com $S$. virgata (100SV) em plantios puro e consorciado com $A$. mangium (50SV:50AM) e E. camaldulensis (50SV:50EC). decorrente do maior estímulo à esporulação promovida pela máxima diversidade de espécies vegetais.

Verificou-se que a revegetação da cava de extração de argila, com plantios puro (100SV) ou consorciados (50SV:50EC; 50SV:50AC), modificou a composição dos FMAs em relação à ADVE (Figura 1). Esse padrão pode estar relacionado a fatores como a presença das raízes das espécies arbóreas, bem como às mudanças nas propriedades do solo (química, física e, ou, biológica), promovidos pelos plantios. A análise de correspondência, que avaliou a relação entre as espécies de FMAs, os atributos químicos $(\mathrm{Ca}, \mathrm{Mg}, \mathrm{P}$, $\mathrm{K}$ e $\mathrm{H}+\mathrm{Al}, \mathrm{COT}, \mathrm{pH})$ do solo, os sistemas de plantio e a ADVE constataram esse fato. As variáveis foram distribuídas em duas dimensões, que explicaram $92,92 \%$ da variabilidade total entre as áreas $(76,23 \%$, para a dimensão 1; e 16,69 \%, para a 2). Ao longo da dimensão 1 (eixo principal), na faixa à direita, encontramse os plantios puro e consorciado de $S$. virgata, que se encontram associados à maioria das variáveis analisadas, enquanto a ADVE ficou disposta na porção esquerda (Figura 2), ou seja, lado oposto aos plantios, estando mais correlacionada com a abundância de esporos (AE) e com a espécie G. macrocarpum. Dessa forma, a presença das espécies arbóreas promovendo menores valores de $\mathrm{pH}$, bem como teores mais elevados de nutrientes ( $\mathrm{Ca}, \mathrm{K}, \mathrm{Mg}, \mathrm{P}$ e $\mathrm{N}$ ) e $\mathrm{COT}$, pode ter contribuído para maior associação das espécies de FMAs a essas áreas.

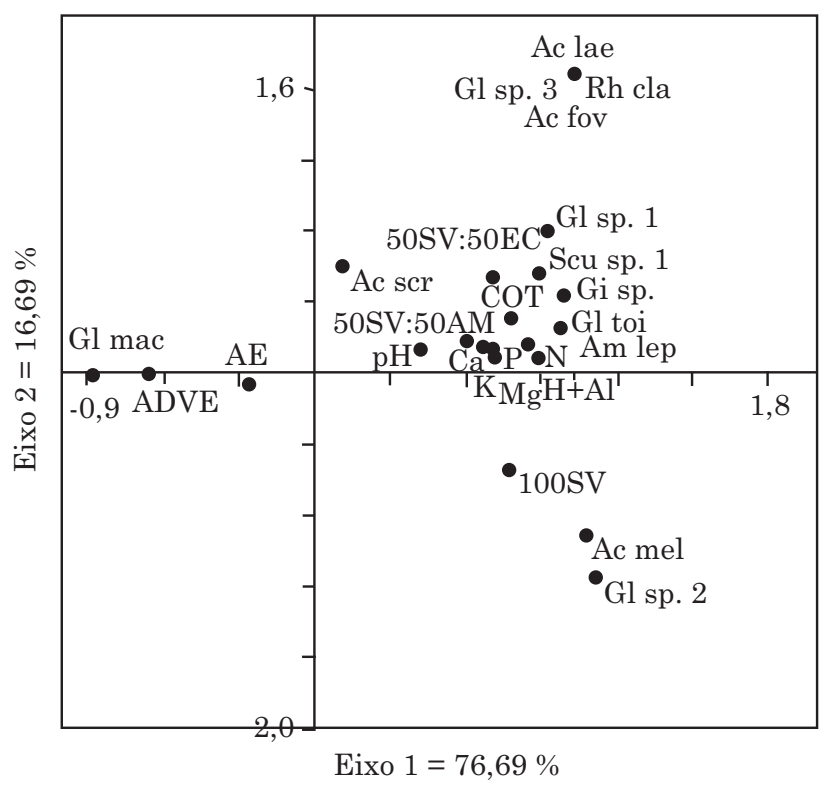

Figura 2. Análise de correspondência para as variáveis químicas e biológicas de amostras de solo de área degradada pela extração de argila, com vegetação espontânea (ADVE) e revegetada com Sesbania virgata em plantios puro (100SV) e consorciado com Acacia mangium (50SV:50AM) e Eucalyptus camaldulensis (50SV:50EC). 
As espécies de FMAs, associadas às áreas da cava revegetadas (100SV, 50SV:50EC e 50SV:50AM), apresentaram número de esporos e índice de abundância e frequência (IAF) variável, dependendo do plantio (Quadro 3). Fato também observado por Mergulhão et al. (2010), quando esses autores avaliaram os FMAs em área de mineração de gesso. A espécie G. macrocarpum, por exemplo, apresentou IAF nulo, baixo e alto, nas áreas de 100SV, 50SV:50EC e 50SV:50AM, respectivamente (Quadro 3). Essa espécie foi uma das inoculadas na fase de produção de mudas, sendo a única entre as demais inoculadas (Claroideoglomus etunicatum e Acaulospora colombiana), que foi verificada na rizosfera dos plantios (50SV:50EC e 50SV:50AM), embora com esporulação muito inferior à observada na ADVE, onde essa não havia sido introduzida por inoculação. Tal padrão pode estar relacionado à falta de adaptação dessas espécies fúngicas, a rizosfera das espécies arbóreas em que foram inoculadas, já que se trata de uma comunidade adaptada a esse tipo de área degradada, ou até mesmo pelo fato de os plantios estabelecidos na área de estudo não estarem estimulando a esporulação das espécies.

É importante ressaltar que a principal fonte de inóculo das espécies de FMAs encontradas neste estudo, nos diferentes sistemas, foi o retorno da camada superficial do solo (mais rica em matéria orgânica), após o processo de extração de argila. Assim, pode-se inferir que a ausência de esporos de uma ou mais espécies de FMAs em determinado sistema (ADVE, 100SV, 50SV:50EC e 50SV:50AM) se deve ao fato da mesma não estar presente no solo ou das espécies vegetais não estarem estimulando a sua esporulação. A ausência de esporos não garante que determinada espécie não esteja presente, pois essa pode estar no solo na forma de hifas ou colonizando fragmentos de raízes, não sendo detectada pelo processo de avaliação utilizado neste estudo.

Somente duas espécies de FMAs foram observadas na ADVE, G. macrocarpum e Acaulospora scrobiculata. Embora a espécie G. macrocarpum tenha apresentado elevado número de esporos (NE) nessa área, foi a espécie $A$. scrobiculata que evidenciou maior índice de abundância e frequência (IAF). Ambas as espécies de FMAs apresentaram grande valor de importância (IAF>30) na ADVE, o que indicou elevada capacidade dessas espécies para tolerar as condições edáficas da área degradada com vegetação espontânea (Quadro 2). Solos com elevados valores de $\mathrm{pH}(\geq 6,8) \mathrm{e}$ baixos teores de COT parecem estimular a esporulação dessas espécies. De acordo com Mergulhão et al. (2010), outros fatores como plantas hospedeiras, biota do solo e clima também podem contribuir para a seleção de FMAs nos ecossistemas.

Quadro 3. Abundância total de esporos (AE) e número médio de esporos por espécie em $50 \mathrm{~cm}^{3} \mathrm{de}$ solo (NE) e índice de abundância e frequência (IAF) das espécies de FMAs na área da cava com vegetação espontânea (ADVE) e revegetada com S. virgata (100SV), em plantios puro e consorciado com A. mangium (50SV:50AM) e E. camaldulensis (50SV:50EC)

\begin{tabular}{|c|c|c|c|c|c|c|c|c|}
\hline \multirow{2}{*}{ Espécie de FMAs } & \multicolumn{2}{|c|}{ 100SV } & \multicolumn{2}{|c|}{ 50SV:50EC } & \multicolumn{2}{|c|}{ 50SV:50AM } & \multicolumn{2}{|c|}{ ADVE } \\
\hline & NE & IAF & NE & IAF & NE & IAF & NE & IAF \\
\hline \multicolumn{9}{|c|}{ Família Glomeraceae } \\
\hline Glomus macrocarpum Tul. \& C. Tul. & - & - & 8 & 10 & 46 & 42 & 1155 & 53 \\
\hline \multicolumn{9}{|c|}{ Rhizophagus clarus (T.H. Nicolson \& N.C. Schenck) } \\
\hline C. Walker \& Schußler & - & - & 3 & 8 & - & - & - & - \\
\hline Glomus sp. 1 & - & - & 3 & 8 & 11 & 12 & - & - \\
\hline Glomus sp. 2 & 30 & 34 & 6 & 15 & - & - & - & - \\
\hline Glomus sp. 3 & - & - & 29 & 21 & - & - & - & - \\
\hline \multicolumn{9}{|c|}{ Família Ambisporaceae } \\
\hline \multicolumn{9}{|l|}{ Ambispora leptoticha (N.C. Schenck \& G.S. Sm.) } \\
\hline C. Walker, Vestberg \& Schußler & 13 & 28 & 11 & 12 & 32 & 29 & - & - \\
\hline \multicolumn{9}{|c|}{ Família Acaulosporaceae } \\
\hline Acaulospora mellea Spain \& N.C. Schenck & 198 & 95 & 32 & 29 & 52 & 37 & - & - \\
\hline Acaulospora scrobiculata Trappe & 7 & 18 & 59 & 49 & 18 & 22 & 71 & 147 \\
\hline Acaulospora foveata Trappe \& Janos & - & - & 3 & 8 & - & - & - & - \\
\hline Acaulospora laevis Gerd. \& Trappe & - & - & 3 & 8 & - & - & - & - \\
\hline \multicolumn{9}{|c|}{ Família Gigasporaceae } \\
\hline Gigaspora sp. & - & - & - & - & 1 & 8 & - & - \\
\hline Scutellospora sp. 1 & - & - & - & - & 4 & 9 & - & - \\
\hline $\mathrm{AE}$ & $275 \mathrm{~b}$ & - & $174 \mathrm{~b}$ & - & $214 \mathrm{~b}$ & - & $1226 \mathrm{a}$ & - \\
\hline
\end{tabular}


Nas áreas com os plantios, outras espécies de FMAs, como G. tortuosum, Glomus sp.2 e A. mellea, foram capazes de se estabelecerem, apresentando alto valor de importância em pelo menos um dos plantios (Quadro 3). G. tortuosum evidenciou elevado valor de importância em quase todos os plantios, exceto no plantio 100SV, ao contrário do Glomus sp.2, que se destacou apenas nessa área.

$\mathrm{Na}$ área com plantio de $100 \mathrm{SV}$, verificaram-se cinco espécies de FMAs (G. tortuosum, Glomus sp.2, Ambispora leptoticha, A. mellea e A. scrobiculata), que apresentaram de moderada a grande importância (IAF>10) nessa área, sendo Acaulospora mellea a espécie que evidenciou maior IAF. No consórcio 50SV:50EC, entre as 11 espécies observadas, cinco ( $G$. macrocarpum, Rhizophagus clarus, Glomus sp.1, Acaulospora foveata e Acaulospora laevis) demonstraram pouca importância ( $\mathrm{IAF} \leq 10)$, quatro (Glomus sp.2, Glomus sp.3, A. leptoticha e Acaulospora mellea) apresentaram moderada importância $(10<\mathrm{IAF} \leq 30)$ e duas $(G$. tortuosum e Acaulospora scrobiculata) evidenciaram grande importância (IAF $>30$ ). No consórcio 50SV:50AM, embora tenha apresentado menor número de espécies de FMAs (oito espécies), quando comparado ao consórcio 50SV:50EC, observou-se o maior número de espécies com grande valor de importância (IAF $>30)$ (Glomus macrocarpum, G. tortuosum e A. mellea) (Quadro 3).

Embora a diversidade de espécies tenha sido mais baixa na ADVE, em relação aos plantios, notou-se maior abundância total de esporos (AE) na área com vegetação espontânea (predomínio de $B$. mutica) (Quadro 3). Odum (1989), em seus conceitos sobre a relação entre estabilidade do sistema e a diversidade de espécies, destacou que em ambientes homogêneos a abundância tende a ser alta, enquanto a diversidade tende a diminuir. Não se verificou diferença entre os sistemas de plantio quanto à abundância total de esporos. Maior AE na ADVE pode ser decorrente da presença de gramíneas, que, em razão do sistema radicular fasciculado delas, é mais favorável à multiplicação dos esporos (Souza et al., 2010) do que das raízes das espécies arbóreas.

No que se refere à proteína do solo relacionada à glomalina, maiores concentrações de PSRG-FE e PSRG-T foram registradas nos plantios, quando comparadas à ADVE (Quadro 4). O aumento nos teores dessas frações em relação à ADVE atingiu cerca de $1.300 \%$ para PSRG-T no plantio 50SV:50EC e de $370 \%$ para PSRG-FE, no plantio 50SV:50AM. Somente na fração PSRG-T observaram-se diferenças significativas entre os plantios, sendo as maiores concentrações encontradas nos plantios 100SV e 50SV:50EC (Quadro 4).

Os fatores que estão relacionados ao controle da produção de PSRG pelos FMAs nos diferentes ambientes ainda não foram completamente esclarecidos; no entanto, o clima, a biota do solo, as
Quadro 4. Proteína do solo relacionada à glomalina total (PSRG-T) e facilmente extraível (PSRGFE) em amostras de solo de área degradada pela extração de argila, com vegetação espontânea (ADVE) e revegetada com S. virgata em plantios puro (100SV) e consorciado com A. mangium (50SV:50AM) e E. camaldulensis (50SV:50EC)

\begin{tabular}{lcc}
\hline Sistema & PSRG-T & PSRG-FE \\
\hline & \multicolumn{2}{c}{$\mathrm{mg} \mathrm{g}^{-1}$ solo } \\
\cline { 2 - 3 } 100SV & $5,90 \mathrm{a}$ & $0,98 \mathrm{a}$ \\
$50 \mathrm{SV}: 50 \mathrm{EC}$ & $7,67 \mathrm{a}$ & $1,23 \mathrm{a}$ \\
$50 \mathrm{SV}: 50 \mathrm{AM}$ & $3,04 \mathrm{~b}$ & $1,31 \mathrm{a}$ \\
ADVE & $0,55 \mathrm{c}$ & $0,28 \mathrm{~b}$ \\
\hline
\end{tabular}

Médias seguidas de mesma letra na coluna não diferem pelo teste Scott-Knott a $5 \%$.

concentrações de nutrientes e, possivelmente, a diversidade de FMAs, bem como o hospedeiro e sua produtividade podem inûuenciar a deposição dessa proteína no solo (Rillig et al., 2001; Oliveira et al., 2009; Silva et al., 2012).

Os maiores teores de PSRG nos plantios em relação à $\mathrm{ADVE}$ podem estar relacionados à maior diversidade de FMAs (Purin \& Rillig, 2007) presente na área revegetada, tendo em vista que a produção dessa glicoproteína difere entre as espécies de FMAs (Wright et al., 1996; Wright \& Upadhyaya, 1998; Wright \& Upadhyaya, 1999; Lovelock et al., 2004). Além disso, as características químicas do solo assim como o pH, que influenciam a simbiose micorrízica, podem ter interferido na produção dessa proteína pelos FMAs e como consequência na sua quantidade no solo (Haddad \& Sarkar, 2003; Rillig et al., 2003; Lovelock et al., 2004). Verificaram-se maiores concentrações de nutrientes $(\mathrm{Ca}, \mathrm{Mg}, \mathrm{P}$ e $\mathrm{K})$ e menores valores de $\mathrm{pH}$ nos plantios, quando comparados a ADVE (Quadro 1).

A maior abundância e a diversidade de organismos da fauna do solo também ajudam a explicar os maiores teores de PSRG nos plantios (Silva et al., 2013). Esse fato pode ter contribuído para maior decomposição das hifas de FMAs e consequente deposição de glomalina no solo. Driver et al. (2005) relataram que pelo fato de a glomalina ser um componente da parede celular das hifas, a maior parte dessa proteína é depositada ao solo após o processo de decomposição por organismos. Silva et al. (2013), avaliando a fauna edáfica, nesse experimento, observaram nos solos sob os plantios a presença de invertebrados que se alimentam de microrganismos (colêmbolos); esses não foram encontrados na área com vegetação espontânea. Os colêmbolos se alimentam, principalmente, de hifas de fungos e, conforme Rusek (1998), ao se alimentarem dessa estrutura, beneficiam o crescimento dos fungos, principalmente pela dispersão de propágulos e pela remoção de hifas velhas, induzindo o crescimento compensatório. 
Teores mais elevados de glomalina no ambiente podem representar maior estoque de $\mathrm{C}$ e $\mathrm{N}$, bem como contribuir para melhor agregação do solo (Wright et al., 2007; Bedini et al., 2007; Fokom et al., 2012). Maiores teores de COT e $\mathrm{N}$ foram observados nos plantios quando comparados à $\mathrm{ADVE}$ (Quadro 1).

\section{CONCLUSÃO}

A revegetação da cava de extração de argila com Sesbania virgata, em plantios puro ou consorciado com Eucalyptus camaldulensis ou Acacia mangium, reduz a abundância de esporos e aumenta a diversidade de espécies de fungos micorrízicos arbusculares e a quantidade de proteína do solo relacionada à glomalina, quando comparada à área degradada com vegetação espontânea.

\section{AGRADECIMENTOS}

À Universidade Estadual do Norte Fluminense Darcy Ribeiro - UENF, à Embrapa Agrobiologia e à Cerâmica Stilbe Ltda.

\section{LITERATURA CITADA}

BEDINI, S.; AVIO, L.E.A. \& GIOVANNETTI, M. Effects of long-term land use on arbuscular mycorrhizal fungi and glomalin-related soil protein. Agric. Ecosyst. Environ., 120:463-466, 2007.

BRADFORD, M.M. A rapid and sensive method for the quantification of microgram quantities of protein utilizing the principle of protein-dye binding. Anal. Biochem., 72:12, 248-254, 1976.

BRANZINI, A.; GONZÁLEZ, R.S. \& ZUBILLAGA, M. Absorption and translocation of copper, zinc and chromium by Sesbania virgata. J. Environ. Manage, 102:50-54, 2012.

BROWER, J.E.; ZAR, J.H. \& VON ENDE, C.N. Field and laboratory methods for general ecology. 3.ed. Dubuque, McGraw-Hill, 1990.

CAMPOS, H. Estatística experimental não-paramétrica. 3.ed. Piracicaba, ESALQ, 1979. 343p.

CARNEIRO, R.F.V.; CARDOZO JÚNIOR, F.M.; PEREIRA, L.F.; ARAÚJO, A.S.F. \& SILVA, G.A. Fungos micorrízicos arbusculares como indicadores da recuperação de áreas degradadas no Nordeste do Brasil. R. Ci. Agron., 43:648657, 2012.

CostA, C.M.C.; MAIA. L.C.; CAVALCANTI, U.M.T. \& NOGUEIRA, R.J.M.C. Influência de fungos micorrízicos arbusculares sobre o crescimento de dois genótipos de aceroleira (Malpighia emarginata D.C.). Pesq. Agropec. Bras., 36:893-901, 2001.
COUTINHO, M.P.; CARNEIRO, J.G.A.; BARROSO, D.G.; RODRIGUES, L.A. \& SIQUEIRA, J. Substrato de cavas de extração de argila enriquecido com subprodutos agroindustriais e urbanos para produção de mudas de sesbânia. R. Árvore, 30:147-153, 2006.

DIAZ-ZORITA, M.; PERFECT, E. \& GROVE, J.H. Disruptive methods for assessing soil structure. Soil Till. Res., 64:3$22,2002$.

DRIVER, J.D.; HOLBEN, W.E. \& RILLIG, M.C. Characterization of glomalin as a hyphal wall component of arbuscular mycorrhizal fungi. Soil Biol. Biochem., 37:101-106, 2005.

FOKOM, R.; ADAMOU, S.; TEUGWA M.C.; BEGOUDE BOYOGUENO, A.D.; NANA, W.L.; NGONKEU, M.E.L.; TCHAMENI, N.S.; NWAGA D.; TSALA NDZOMO, G. \& AMVAM ZOLLO, P.H. Glomalin related soil protein, carbon, nitrogen and soil aggregate stability as affected by land use variation in the humid Forest zone of south Cameroon. Soil Till. Res., 120:69-75, 2012.

GERDERMANN, J.N. \& NICOLSON, T.H. Spores of mycorrhizal Endogone species extracted from soil by wet sieving and decanting. Trans. Brit. Mycol. Soc., 46:235$244,1963$.

HADDAD, M.J. \& SARKAR, D. Glomalin, a newly discovered component of soil organic matter: Part II - Relationship with soil properties. Environ. Geosci., 10:99-106, 2003.

HAMMER, O.; HARPER, D.A. \& RYAN, P.D. PAST Paleontological Statistics ver.1.12, 2004. Disponível em: $<$ http://www.folk.uio.no/ohammer/past>. Acesso em: 15 jan. 2013.

KOSKE, R.E. \& GEMMA, J.N. Mycorrhizae and sucession in plantings of beachgrass in sand dunes. Am. J. Bot., 84:118$130,1997$.

KOSKE, R.E.; GEMMA, J.N. \& JACKSON, N. Mycorrhizal fungi associated with three species of turfgrass. Can. J. Bot., 75:320-332, 1997.

LEAKE, J.; JOHNSON, D.; DONNELLY, D.; MUCKLE, G.; BODDY, L. \& READ, D. Networks of power and influence: The role of mycorrhizal mycelium in controlling plant communities and agroecosystem functioning. Can. J. Bot., 82:1016-1045, 2004

LOVELOCK, C.E.; WRIGHT, S.F. \& NICHOLS, K.A. Using glomalin as an indicator for arbuscular mycorrhizal hyphal growth: an example from a tropical rain forest soil. Soil Biol. Biochem., 36:1009-1012, 2004.

MERGULHÃO, A.C.E.S.; BURITY, H.A.; SILVA, F.S.B.; PEREIRA, S.V. \& MAIA, L.C. Glomalin production and microbial activity in soils impacted by gypsum mining in a Brazilian semiarid area. Am. J. Agric. Biol. Sci., 5:422429, 2010.

NOGUEIRA, M.A. \& CARDOSO, E.J.B.N. Produção de micélio externo por fungos micorrízicos arbusculares e crescimento da soja em função de doses de fósforo. R. Bras. Ci. Solo, 24:329-338, 2000.

ODUM, E.P. Ecologia. Rio de Janeiro, Guanabara Koogan, 1989. 639p. 
OLIVEIRA, J.R.G.; SOUZA, R.G.; SILVA, F.S.B.; MENDES, A.S.M. \& YANO-MELO, A.M. O papel da comunidade de fungos micorrízicos arbusculares (FMA) autóctones no desenvolvimento de espécies vegetais nativas em área de dunas de restinga revegetadas no litoral do Estado da Paraíba. R. Bras. Bot., 32:663-670, 2009.

PIOTROWSKI, J.S.; DENICH, T.; KLIRONOMOS, J.N.; GRAHAM, J.M. \& RILLIG, M.C. The effects of arbuscular mycorrhizas on soil aggregation depend on the interaction between plant and fungal species. New Phytol., 164:365373, 2004.

POUYÚ-ROJAS, E.; SIQUEIRA, J.O. \& SANTOS, J.G.D. Compatibilidade simbiótica de fungos micorrízicos arbusculares com mudas de espécies arbóreas tropicais. R. Bras. Ci. Solo, 30:413-424, 2006.

PURIN, S. Fungos micorrízicos arbusculares: Atividade, diversidade e aspectos funcionais em sistemas de produção de maçã. Florianópolis, Universidade do Estado de Santa Catarina, 2005. 147p. (Dissertação de Mestrado)

PURIN, S. \& RILLIG, M.C. The arbuscular mycorrhizal fungal protein glomalin: Limitations, progress, and a new hypothesis for its function. Pedobiologia, 51:123-130, 2007.

RILLIG, M.C.; RAMSEY, P.; MORRIS, S. \& PAUL, E. Glomalin, an arbuscular-mycorrhizal fungal soil protein, responds to soil-use change. Plant Soil, 253:293-299, 2003.

RILLIG, M.C. Arbuscular mycorrhizae, glomalin, and soil aggregation, Can. J. Soil Sci., 84:355-363, 2004.

RILLIG, M.C.; WRIGHT, S.F.; NICHOLS, K.A.; SCHMIDT, W.F. \& TORN, M.S. Large contribution of arbuscular mycorrhizal fungi to soil carbon pools in tropical forest soils. Plant Soil, 233:167-177, 2001.

RODRIGUES, L.A.; MARTINS, M.A. \& SALOMÃO, M.S.M.B. Uso de micorrizas e rizóbio em cultivo consorciado de eucalipto e sebânia. I - Crescimento, absorção e transferência de nitrogênio entre plantas. R. Bras. Ci. Solo, 27:583-591, 2003 .

RUSEK, J. Biodiversity of Collembola and their functional role in the ecosystem. Biodiv. Conserv., 7:1207-1219, 1998.

SAMÔR, O.J.M. Comportamento de mudas de Sesbania virgata e Anadenanthera macrocarpa, produzidas em diferentes recipientes e substratos, destinadas à recuperação de áreas degradadas pela extração de argila. Campos dos Goytacazes, Universidade Estadual do Norte Fluminense Darcy Ribeiro, 1999. 70p. (Dissertação de Mestrado)

SANTIAGO, A.R.; BARROSO, D.G.; MENDONÇA, A.V.R.; FREITAS, T.A.S.; LAMÔNICA, K.R. \& CARNEIRO, J.G.A. Influência do sistema de plantio sobre atributos químicos de substrato de cava de extração de argila. Floresta, 39:597-604, 2009.

SANTOS, D.R.; MOREIRA, F.M.S. \& SIQUEIRA, J.O. Fósforo, fungo micorrízico e rizóbio no crescimento, nodulação e fixação biológica do nitrogênio em Sesbania virgata (Cav.) e Sesbania rostrata (Bram). In: FERTBIO. Caxambu, 1997. Anais... Caxambu, 1997. p.772.

SCHENCK, N.C. \& PEREZ, Y. Manual for the identification of VA mycorrhizal fungi. Gainesville, University of Florida, 1988. $240 \mathrm{p}$
SCHIAVO, J.A. Revegetação de áreas degradadas pela extração de argila, com espécies micorrizadas de Acacia mangium, Sesbania virgata e Eucalyptus camaldulensis. Campos dos Goytacazes, Universidade Estadual do Norte Fluminense Darcy Ribeiro, 2005. 117p. (Tese de Doutorado)

SCHIAVO, J.A.; MARTINS, M.A. \& RODRIGUES, L.A. Crescimento de mudas de Acacia mangium, Sesbania virgata e Eucalytpus camaldulensis, inoculadas com fungos micorrízicos, em casa-de-vegetação e em cava-deextração de argila. Acta Sci. Agron., 32:171-178, 2010.

SILVA, C.F. Atributos químicos e biológicos em cavas de extração de argila revegetadas com eucalipto e leguminosas. Campos dos Goytacazes, Universidade Estadual do Norte Fluminense Darcy Ribeiro, 2009. 172p. (Tese de Doutorado)

SILVA, C.F.; SIMÕES-ARAÚJO, J.L.; SILVA, E.M.R.; PEREIRA, M.G.; FREITAS, M.S.M.; SAGGIN JÚNIOR, O.J. \& MARTINS, M.A. Fungos micorrízicos arbusculares e proteína do solo relacionada à glomalina em área degradada por extração de argila e revegetada com eucalipto e acácia. Ci. Flor., 22:749-761, 2012.

SILVA, C.F.; MARTINS, M.A.; SILVA, E.M.R.; PEREIRA, M.G; CORREIA, M.E.F. Influência do sistema de plantio sobre atributos dendrométricos e fauna edática, em área degradada pela extração de argila. R. Bras. Ci. Solo, $37: 1742-1751,2013$

SNEDECOR, W. \& COCHRAN, W.G. Statistical methods. 8.ed. Ames, Iowa State University Press, 1989. 502p.

SOUSA, C.S.; MENEZES, R.S.C.; SAMPAIO, E.V.S.B. \& LIMA, F.S.L. Glomalina: Características, produção, limitações e contribuição nos solos. Semina: Ci. Agron., 33:3033-3044, 2012 .

SOUZA, G.I.A.; CAPRONI, A.L.; GRANHA, J.R.D.O.; SOUCHIE, E.L. \& BERBARA, R.L.L. Arbuscular mycorrhizal fungi in agricultural and forest systems. Global Sci. Technol., 3:1-9, 2010.

WRIGHT, S.F. \& UPADHYAYA, A. A survey of soils for aggregate stability and glomalin, a glycoprotein produced by hyphae of arbuscular mycorrhizal fungi. Plant Soil, 198:97-107, 1998.

WRIGHT, S.F. \& UPADHYAYA, A. Quantification of arbuscular mycorrhizal fungi activity by the glomalin concentration on hyphal traps. Mycorrhiza, 8:283-285, 1999.

WRIGHT, S.F.; FRANKE-SNYDER, M.; MORTON, J.B. \& UPADHYAYA, A. Time-course study and partial characterization of a protein on hyphae of arbuscular mycorrhizal fungi during active colonization of roots. Plant Soil, 181:193-203, 1996.

WRIGHT, S.F.; GREEN, V.S. \& CAVIGELLI, M.A. Glomalin in aggregate size classes from three different farming systems. Soil Till. Res., 94:546-549, 2007.

WU, B.; HOGETSU, T.; ISOBE, K. \& RYUICHI, I. Community structure of arbuscular mycorrhizal fungi in a primary successional volcanic desert on the southeast slope of Mount Fuji. Mycorrhiza, 17:495-506, 2007. 